\title{
TITLE:
}

\section{The role of neurogenesis in olfaction-dependent behaviors.}

$\operatorname{AUTHOR}(S)$ :

Kageyama, Ryoichiro; Imayoshi, Itaru; Sakamoto, Masayuki

\section{CITATION:}

Kageyama, Ryoichiro ...[et al]. The role of neurogenesis in olfactiondependent behaviors.. Behavioural brain research 2012, 227(2): 459-463

ISSUE DATE:

2012-02-14

URL:

http://hdl.handle.net/2433/153289

\section{RIGHT:}

C 2011 Elsevier B.V.; この論文は出版社版でありません。引用の際には 出版社版をご確認ご利用ください。; This is not the published version. Please cite only the published version. 


\section{The role of neurogenesis in olfaction-dependent behaviors}

$$
\text { Ryoichiro Kageyama }{ }^{1,2 *} \text {, Itaru Imayoshi }{ }^{1,3} \text {, and Masayuki Sakamoto }{ }^{1,2,4}
$$

${ }^{1}$ Institute for Virus Research, Kyoto University, Kyoto 606-8507, Japan; ${ }^{2}$ Japan Science and Technology Agency, CREST, Kyoto 606-8507, Japan; ${ }^{3}$ Japan Science and Technology Agency, PRESTO, Kyoto 606-8507, Japan; ${ }^{4}$ Kyoto University Graduate School of Biostudies, Kyoto 606-8502

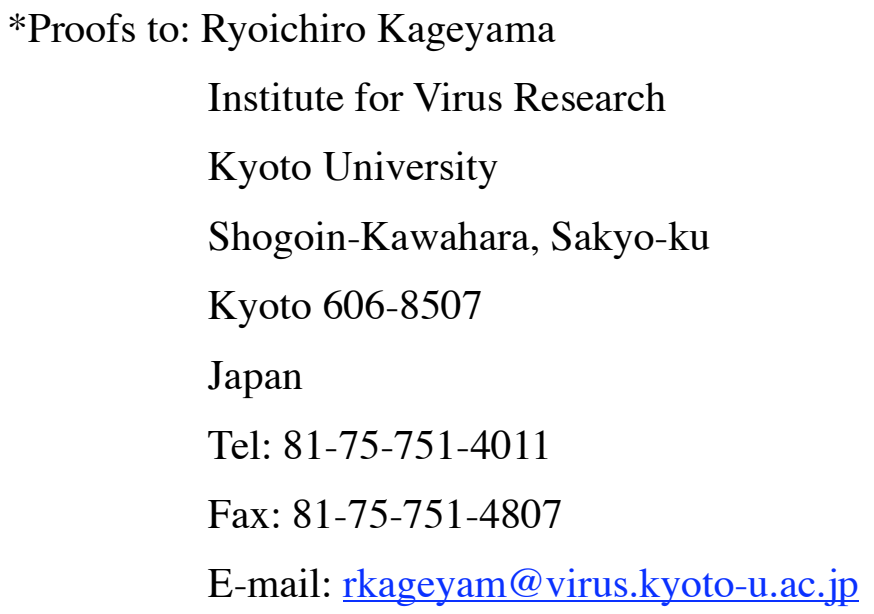




\begin{abstract}
Newly born neurons continuously migrate into the main and accessory olfactory bulbs and modulate the output of projection neurons. Despite some contradictory results, it is becoming clear that these newly born neurons play an important role in the response to some odorant cues. In this minireview, we discuss the recent findings surrounding the functional significance of adult neurogenesis in olfaction-dependent behaviors.
\end{abstract}

\title{
Introduction
}

There are many neural stem cells in two brain regions of adult mammals, the subventricular zone (SVZ) of the lateral ventricles and the subgranular zone (SGZ) of the hippocampal formation $[23,36,38]$. These neural stem cells are mostly quiescent under the control of Notch, Shh and BMP signaling [1,3,6,8,16,24,28] but occasionally divide to give rise to transit-amplifying cells, which proliferate and generate many neurons. Neurons born in the SVZ migrate via the rostral migratory stream into the olfactory bulb (Fig. 1), while neurons born in the SGZ migrate into the hippocampal dentate gyrus [23,38]. The functional significance of adult neurogenesis in hippocampal-dependent learning and memory has been well documented [9,38], but the role of such neurogenesis in olfactory activity is rather obscure.

The olfactory bulb consists of two structures, the main olfactory bulb and the accessory olfactory bulb (Fig. 1). The main olfactory bulb is involved in the cognitive response to chemical cues detected by the main olfactory epithelium, while the accessory olfactory bulb is involved in the instinctive response to pheromonal cues detected by the vomeronasal organ, although this functional difference between the main and accessory olfactory bulbs is not absolute $[4,10]$. The vast majority of neurons born in the SVZ differentiate into granule cells while others become periglomerular cells in the main olfactory bulb $[23,36,38]$. Some neurons born in the SVZ migrate into the accessory olfactory bulb (Fig. 1) [29]. All these neurons are local interneurons that modulate the output of projection neurons (mitral and tufted cells) [36]. Interestingly, newly born neurons exhibit different synaptic plasticity from that of mature neurons: theta-burst stimulation induces long-term potentiation in newly born neurons but not in mature neurons [27]. Furthermore, aged mice, which have more mature neurons and fewer newly born neurons than young adult mice, are impaired at fine olfactory discrimination $[11,25]$. These data suggest that newly born neurons might be required 
for optimal olfactory activity. However, the precise roles of adult neurogenesis in odor processing remain to be determined.

To understand the functional significance of adult neurogenesis in olfactory activity, researchers have used many methods to ablate newly born neurons in animals, and these animals have been used for behavioral analyses [9]. However, there are some discrepancies among the published reports of neurogenesis-dependent odor-associated behaviors, complicating the interpretation of the significance of neurogenesis. These discrepancies may be due to different ablation methods and different behavioral tests. In this minireview, we discuss the recent data about the functional significance of adult neurogenesis in olfactory activity.

\section{Approaches for ablating newly born neurons}

Ablation of newly born neurons has been attempted to understand their functions in the adult brain [9]. The most common ablation methods are treatments with $\gamma$-ray irradiation or anti-mitotic drugs, such as methylazoxymethanol (MAM), to kill dividing neural stem/progenitor cells. For $\gamma$-ray treatment, a brain area encompassing the SVZ or SGZ is exposed to irradiation while the other brain region is protected with lead shields (Fig. 2a). This method allows region-specific inhibition of neurogenesis, although the longterm effect on the SGZ neurogenesis by the SVZ irradiation was not analyzed. For antimitotic drug treatment, an appropriate dose is injected subcutaneously or intraperitoneally. This method inhibits neurogenesis in both the SVZ and SGZ. Drug can be also specifically applied to the SVZ by implanting an osmotic minipump into the lateral ventricle (Fig. 2b), although neurogenesis in the SGZ is also affected to a lesser extent $[5,34]$. It was reported that about $60-90 \%$ of neurogenesis in the SVZ is reduced by $\gamma$-ray treatment or anti-mitotic drugs $[5,12,20,34,35]$. Although these methods are effective, the efficiency for inhibition of neurogenesis could be variable depending on treatment protocols, and neurogenesis could recover later because quiescent neural stem cells are rather resistant to $\gamma$-ray irradiation and anti-mitotic drugs. In addition, these treatments also cause severe side effects, such as inflammation, on mature neurons, which might affect the mood and behavior of the animals. These disadvantages may lead to inconsistency in behavior defects observed after such treatments.

To overcome such disadvantages, genetic methods for ablating newly born neurons have been developed. One such method uses Nestin-CreER ${ }^{\mathrm{T} 2}$ mice, which 
express tamoxifen-inducible Cre in neural stem/progenitor cells under the control of the Nestin promoter/enhancer (Fig. 2c). These mice were crossed with NSE-loxP-StoploxP-DTA (NSE-DTA) mice, in which Cre induces loxP-mediated deletion of a stop cassette and allows the neuron-specific enolase (NSE) promoter to drive expression of diphthelia toxin fragment A (DTA, Fig. 2b) $[14,15]$. In Nestin-CreER ${ }^{\mathrm{T} 2}$;NSE-DTA nice, Cre becomes active in neural stem/progenitor cells after tamoxifen administration, but DTA is not expressed in these cells because the NSE promoter is inactive (Fig. 2c). However, when the cells begin neuronal differentiation, the NSE promoter becomes active and induces expression of DTA, which kills the cells (Fig. 2c). Thus, in these mice, neural stem cells in the SVZ and SGZ do not die, but only newly born neurons are efficiently ablated after tamoxifen treatment without any noticeable side effects on mature neurons: this method achieved about $96 \%$ reduction of neurogenesis in the main olfactory bulb compared to controls, forming spaces void of neurons [15]. While neurogenesis in the SVZ and SGZ is simultaneously blocked in these mice, more restricted ablation is also attempted by using region- or neuronal subtype-specific promoters instead of the NSE promoter [our unpublished data]. These transgenic mice can be used for behavior tests, and it will be important to compare the results obtained from such genetic methods and those obtained from $\gamma$-ray irradiation or anti-mitotic drug treatments to reconcile inconsistent results.

\section{Behavioral tests for the response to chemical cues}

Odor experiences affect the survival of newly born neurons, suggesting that neurogenesis is involved in odor-associated activities [2,36]. To understand the significance of neurogenesis in olfaction, various olfactory behavioral tests have been conducted in mice following manipulation of neurogenesis. One such test is to determine odor detection threshold by measuring the sniffing time of various odors. Untreated mice spent more time investigating some odors at $10^{-4}$ dilution than they did mineral oil, while mice whose neurogenesis was blocked by continuous infusion of the antimitotic drug cytosine arabinoside (AraC) did not [5]. Thus, these mice could not differentiate between odors at $10^{-4}$ dilution and mineral oil, suggesting that odor detection was less sensitive in the absence of neurogenesis. At higher concentrations such as $10^{-3}$ dilution, there was no difference in investigation time for detection of odors between treated and untreated mice. However, when the same odors at this 
concentration were exposed twice for 5 min each, with a 60-min interval (habituationdishabituation tests), untreated mice spent significantly less time investigating during the second exposure, whereas treated mice spent similar lengths of time during the two exposures [5]. Because it is well known that mice spend less time investigating familiar odors, these results suggest that odor memory is lost during a 60-min interval without neurogenesis. Another study reported similar results [26]. Thus, continuous neurogenesis is required for optimal odor detection threshold and for short-term odor memory. In agreement with this idea, it was reported that newly born neurons preferentially expressed the immediate early gene Zif268, an indicator of activation, in response to odor stimulation, and that blocking neurogenesis reduced the number of newly born Zif268-expressing neurons [26]. Together, these findings suggest that newly born neurons are preferentially involved in processing odor memory.

However, not all findings have supported this. In odor reward threshold test, tamoxifen-treated Nestin-CreER ${ }^{\mathrm{T} 2}$;NSE-DTA mice showed apparently normal sensitivity [30]. Furthermore, in habituation-dishabituation tests, Mice treated with $\gamma$-ray irradiation to block neurogenesis showed no significant differences from untreated mice [20], suggesting that spontaneous odor discrimination is not affected in these mice. Similar results were observed in Bax-null mice with reduced programmed cell death and interrupted migration of newly born neurons into the olfactory bulb [18]. Although these mice had very few newly born olfactory bulb neurons at 12 months, they displayed normal behaviors in habituation-dishabituation tests, suggesting that neurogenesis is not required for odor discrimination and short-term odor memory [18]. The discrepancies between these two findings may be due to different ablation methods or efficiencies, but further analysis is required to clarify this issue.

An odor-reward association memory test in the previously described, tamoxifen-treated Nestin-CreER ${ }^{\mathrm{T} 2}$;NSE-DTA mice suggested that continuous neurogenesis is not required for odor memory. Two related odors (enantiomers), one mixed with sugar and the other without sugar, were given to food-restricted mice four times a day; after four days of training, each mouse was placed in a cage, in which both odors, without sugar, were placed under the bedding at separate sites (odor-reward association memory test). Both wild-type and mutant mice spent significantly more time digging at the site of the sugar-associated odors than at the site of the non-sugarassociated odors. The same behavior was observed one day, one week, and even two 
months after training [15], strongly indicating that continuous neurogenesis is not required to discriminate similar odors or for either short- or long-term retention of the odor-associated memory (Table 1). The apparently conflicting results between habituation-dishabituation and odor-reward association memory tests may be due to differences in motivation. The former test is based on spontaneous behaviors, while the latter test provides mice with strong motivation to get a reward, and mutant mice with a strong motivation may overcome any disadvantage resulting from a lack of neurogenesis.

However, conflicting results were also reported following similar motivationdependent tests. Although the mice treated with $\gamma$-ray irradiation learned sugarassociated versus non-sugar-associated odors as well as the untreated mice, 30 days after training they made more errors (they chose non-sugar-associated odors more frequently) than untreated mice, suggesting that long-term olfactory memory is impaired in these mice [20]. In another reward-associated odor memory test, mice were trained on a 2-hole board apparatus; one hole had both odor and reward while the other had neither odor nor reward. Mice treated with continuous infusion of AraC to block neurogenesis were able to learn sugar-associated odors as well as untreated mice; however, while untreated mice retained the odor-associated memory for at least five days, the treated mice did not [34], suggesting that neurogenesis is required for retention of the odor-associated memory. Fear conditioning tests were also used to examine odor memories. Mice that received odor stimulation and footshock (odor-cued fear conditioning) exhibited freezing behavior in response to the odor. Although $\gamma$-ray irradiated mice showed normal acquisition of odor-cued fear conditioning, they froze less in response to the odor one day later [35], suggesting that olfactory memories are not properly retained without continuous neurogenesis, even when the mice are strongly conditioned. The precise reason for these discrepancies is currently unknown. One possibility is that irradiation and antimitotic drug treatment, which not only kill dividing progenitors but also damage mature neurons, result in severer defects in olfactory memory than genetic ablation of newly born neurons, because mice with genetically inhibited neurogenesis (Bax-null mice and tamoxifen-treated Nestin-CreERT2;NSEloxP-Stop-loxP-DTA mice) displayed no apparent defects in either habituationdishabituation or odor-reward association memory tests (Table 1) [15,18].

Olfactory behavior was also examined in mice lacking the neural cell 
adhesion molecule NCAM. The migration of neurons to the olfactory bulb is impaired in these mice, leading to about $40 \%$ reduction in the granule cell layer of the olfactory bulb [13]. In habituation-dishabituation tests, wild-type mice spent more time investigating a novel odor than a familiar odor, whereas mutant mice did not investigate novel odors longer than familiar ones, suggesting that odor discrimination is affected in NCAM-null mice [13]. However, NCAM-null mice were able to discriminate different odors and learn the odor reward-associated task. Both wild-type and NCAM-null mice spent significantly more time digging at the site of sugar-associated odors than at the site of non-sugar-associated odors [31], indicating that NCAM-null mice can learn odorassociated tasks and retain the odor-associated memory at least for one day. It is likely that in this test, the mice were well motivated to learn the odor discrimination task. These results strongly suggest that reduced numbers of newly born neurons in the olfactory bulb does not affect odor discrimination or short-term retention of strongly conditioned olfactory memory.

\section{Behavioral tests for the response to pheromonal cues}

In addition to the cognitive recognition of smell, the instinctive response to pheromonal cues is also processed by the main and accessory olfactory systems. Recent studies indicate that neurogenesis plays an essential role in pheromone-associated activities. Olfactory activities are very important for the maintenance of pregnancy $[7,17,32]$, and pregnancy induces biphasic stimulation of neurogenesis in the SVZ, leading to a biphasic increase in the production of both granule cells and periglomerular cells in the olfactory bulb [33]. The first peak of neurogenesis occurs around gestation day 7, neurogenesis returns to baseline at gestation day 14 , and the second peak occurs around postpartum day 7. This pregnancy-induced stimulation of neurogenesis is mediated by prolactin, which directly activates proliferation and neuronal differentiation of the SVZ neural stem cells [19,33]. Reduced prolactin levels following the administration of the dopamine D2-receptor agonist bromocriptine led to decreased neurogenesis and impaired maternal behaviors [19]. In support of this observation, pregnant mice treated with MAM showed defects in maternal behaviors [19]. Neurogenesis in females is also induced by dominant male pheromones and seems to be important for sexual behaviors $[21,29]$. In agreement with this idea, we have recently found that tamoxifen-treated Nestin-CreER ${ }^{\mathrm{T} 2}$;NSE-DTA mice, in which neurogenesis is genetically blocked, exhibit 
severe deficits in pheromone-associated behaviors [our unpublished data], suggesting that continuous neurogenesis is essential for such gender-specific activities.

However, conflicting results were also reported (Table 1). Mice treated with $\gamma$ ray irradiation in the SVZ, which showed 63\% reduction of neurogenesis in the main olfactory bulb, seemed to display normal sexual and maternal behaviors [12]. The discrepancy between this study and others remains to be clarified, but one possibility is that in this $\gamma$-ray irradiation experiment the remaining ability for neurogenesis could be sufficient for prolactin-dependent functions. Another possibility is that neurogenesis in the dentate gyrus is also involved in sexual and maternal behaviors, because in the $\gamma$-ray irradiation study, neurogenesis was inhibited only in the SVZ while in other studies neurogenesis was blocked in the SVZ and SGZ. It would be interesting to compare sexual and maternal behaviors when neurogenesis is inhibited only in the SGZ.

Induced neurogenesis is also observed in male mice. When they remain with their female partners during pregnancy and post-partum, they exhibit retrieval behavior toward their pups. Furthermore, these males can discriminate between their offspring and those of others, even after they are separated from their offspring for three weeks [22]. In these males, neurogenesis is significantly activated, and without such increased neurogenesis, they fail to discriminate between their offspring and non-offspring [22]. This increased neurogenesis appears to depend on the odor of their offspring and is mediated by prolactin [22]. These results suggest that neurogenesis is important for males to perform offspring recognition.

The above results indicate that olfactory neurogenesis is significantly enhanced when sexual and maternal behaviors are required, and suggest that neurogenesis plays a role in such pheromone-associated behaviors, although there are some conflicting results. To clarify the inconsistencies, the functional significance of adult neurogenesis in pheromone-associated behaviors should be further examined by using various ablation methods.

\section{Concluding remarks}

While treatments with $\gamma$-ray irradiation or anti-mitotic drugs are very effective, these treatments cause severe side effects, resulting in some inconsistent results. Recently developed genetic methods are very efficient, and it will be important to compare the results obtained from the conventional methods and those obtained from the genetic 
methods to reconcile inconsistent results. It will be also important to standardize behavior test protocols to avoid laboratory-specific variations.

In spite of some discrepancies, genetic ablation experiments clearly showed that continuous neurogenesis is mostly dispensable for discrimination of similar odors and short- and long-term odor memory, at least when strongly motivated, suggesting that olfactory functions are well maintained in the absence of continuous neurogenesis. Neurogenesis is significantly induced when sexual and maternal behaviors are required, and at least some studies reported that such behaviors depend on continuous neurogenesis. Odor memory of new partners and pups and proper behaviors to such odors are essential for species preservation, and it is reasonable that newly born neurons in the adult brain play more important roles in sexual and maternal behaviors to new olfactory memories than in discrimination and memory of chemical odors. However, the mechanisms by which newly born neurons are integrated into the preexisting neural circuit and of how they regulate odor-associated behaviors, particularly pheromonedependent instinctive behaviors, are largely unknown. Further analysis, such as regionand neuronal subtype-specific ablation, will be required to address these issues.

\section{References}

1. Ables JL, Decarolis NA, Johnson MA, Rivera PD, Gao Z, Cooper DC, Radtke F, Hsieh J, Eisch AJ. Notch1 is required for maintenance of the reservoir of adult hippocampal stem cells. J Neurosci. 2010;30(31):10484-92.

2. Alonso M, Viollet C, Gabellec MM, Meas-Yedid V, Olivo-Marin JC, Lledo PM. Olfactory discrimination learning increases the survival of adult-born neurons in the olfactory bulb. J Neurosci. 2006;26(41):10508-13.

3. Balordi F, Fishell G. Hedgehog signaling in the subventricular zone is required for both the maintenance of stem cells and the migration of newborn neurons. J Neurosci. 2007;27(22):5936-47.

4. Baum MJ, Kelliher KR. Complementary roles of the main and accessory olfactory systems in mammalian mate recognition. Annu Rev Physiol. 2009;71:141-60.

5. Breton-Provencher V, Lemasson M, Peralta MR 3rd, Saghatelyan A. Interneurons produced in adulthood are required for the normal functioning of the olfactory bulb network and for the execution of selected olfactory behaviors. J Neurosci. 2009;29(48):15245-57. 
6. Breunig JJ, Silbereis J, Vaccarino FM, Sestan N, Rakic P. Notch regulates cell fate and dendrite morphology of newborn neurons in the postnatal dentate gyrus. Proc Natl Acad Sci U S A. 2007;104(51):20558-63.

7. Bruce HM. An exteroceptive block to pregnancy in the mouse. Nature 1959;184:105.

8. Chapouton P, Skupien P, Hesl B, Coolen M, Moore JC, Madelaine R, Kremmer E, Faus-Kessler T, Blader P, Lawson ND, Bally-Cuif L. Notch activity levels control the balance between quiescence and recruitment of adult neural stem cells. J Neurosci. 2010;30(23):7961-74.

9. Deng W, Aimone JB, Gage FH. New neurons and new memories: how does adult hippocampal neurogenesis affect learning and memory? Nat Rev Neurosci. 2010;11(5):339-50.

10. Dulac C, Wagner S. Genetic analysis of brain circuits underlying pheromone signaling. Annu Rev Genet. 2006;40:449-67.

11. Enwere E, Shingo T, Gregg C, Fujikawa H, Ohta S, Weiss S. Aging results in reduced epidermal growth factor receptor signaling, diminished olfactory neurogenesis, and deficits in fine olfactory discrimination. $\mathrm{J}$ Neurosci. 2004;24(38):8354-65.

12. Feierstein CE, Lazarini F, Wagner S, Gabellec M-M, de Chaumont F, Olivo-Marin J-C, Boussin FD, Lledo P-M, Gheusi G. Disruption of adult neurogenesis in the olfactory bulb affects social interaction buut not maternal behavior. Front Neurosci 2010:4:176.

13. Gheusi G, Cremer H, McLean H, Chazal G, Vincent JD, Lledo PM. Importance of newly generated neurons in the adult olfactory bulb for odor discrimination. Proc Natl Acad Sci USA. 2000;97(4):1823-8.

14. Imayoshi I, Ohtsuka T, Metzger D, Chambon P, Kageyama R. Temporal regulation of Cre recombinase activity in neural stem cells. Genesis. 2006;44(5):233-8.

15. Imayoshi I, Sakamoto M, Ohtsuka T, Takao K, Miyakawa T, Yamaguchi M, Mori K, Ikeda T, Itohara S, Kageyama R. Roles of continuous neurogenesis in the structural and functional integrity of the adult forebrain. Nat Neurosci. 2008;11(10):1153-61.

16. Imayoshi I, Sakamoto M, Yamaguchi M, Mori K, Kageyama R. Essential roles of Notch signaling in maintenance of neural stem cells in developing and adult brains. 
J Neurosci. 2010;30(9):3489-98.

17. Kaba H, Hayashi Y, Higuchi T, Nakanishi S. Induction of an olfactory memory by the activation of a metabotropic glutamate receptor. Science. 1994;265(5169):2624.

18. Kim WR, Kim Y, Eun B, Park OH, Kim H, Kim K, Park CH, Vinsant S, Oppenheim RW, Sun W. Impaired migration in the rostral migratory stream but spared olfactory function after the elimination of programmed cell death in Bax knock-out mice. J Neurosci. 2007;27(52):14392-403.

19. Larsen CM, Grattan DR. Prolactin-induced mitogenesis in the subventricular zone of the maternal brain during early pregnancy is essential for normal postpartum behavioral responses in the mother. Endocrinology. 2010;151(8):3805-14.

20. Lazarini F, Mouthon MA, Gheusi G, de Chaumont F, Olivo-Marin JC, Lamarque S, Abrous DN, Boussin FD, Lledo PM. Cellular and behavioral effects of cranial irradiation of the subventricular zone in adult mice. PLoS One. 2009;4(9):e7017.

21. Mak GK, Enwere EK, Gregg C, Pakarainen T, Poutanen M, Huhtaniemi I, Weiss S. Male pheromone-stimulated neurogenesis in the adult female brain: possible role in mating behavior. Nat Neurosci. 2007;10(8):1003-11.

22. Mak GK, Weiss S. Paternal recognition of adult offspring mediated by newly generated CNS neurons. Nat Neurosci. 2010;13(6):753-8.

23. Ming GL, Song H. Adult neurogenesis in the mammalian central nervous system. Annu Rev Neurosci. 2005;28:223-50.

24. Mira H, Andreu Z, Suh H, Lie DC, Jessberger S, Consiglio A, San Emeterio J, Hortigüela R, Marqués-Torrejón MA, Nakashima K, Colak D, Götz M, Fariñas I, Gage FH. Signaling through BMPR-IA regulates quiescence and long-term activity of neural stem cells in the adult hippocampus. Cell Stem Cell. 2010;7(1):78-89.

25. Mirich JM, Williams NC, Berlau DJ, Brunjes PC. Comparative study of aging in the mouse olfactory bulb. J Comp Neurol. 2002;454(4):361-72.

26. Moreno MM, Linster C, Escanilla O, Sacquet J, Didier A, Mandairon N. Olfactory perceptual learning requires adult neurogenesis. Proc Natl Acad Sci USA. 2009;106(42):17980-5.

27. Nissant A, Bardy C, Katagiri H, Murray K, Lledo PM. Adult neurogenesis promotes synaptic plasticity in the olfactory bulb. Nat Neurosci 2009;12(6):72830. 
28. Nyfeler Y, Kirch RD, Mantei N, Leone DP, Radtke F, Suter U, Taylor V. Jagged1 signals in the postnatal subventricular zone are required for neural stem cell selfrenewal. EMBO J. 2005;24(19):3504-15.

29. Oboti L, Savalli G, Giachino C, De Marchis S, Panzica GC, Fasolo A, Peretto P. Integration and sensory experience-dependent survival of newly-generated neurons in the accessory olfactory bulb of female mice. Eur J Neurosci. 2009;29(4):679-92.

30. Sakamoto M, Imayoshi I, Ohtsuka T, Yamaguchi M, Mori K, Kageyama R. Continuous neurogenesis in the adult forebrain is required for innate olfactory responses. Proc Natl Acad Sci USA 2011;108(20):8479-8484

31. Schellinck HM, Arnold A, Rafuse VF. Neural cell adhesion molecule (NCAM) null mice do not show a deficit in odour discrimination learning. Behav Brain Res. 2004;152(2):327-34.

32. Serguera C, Triaca V, Kelly-Barrett J, Banchaabouchi MA, Minichiello L. Increased dopamine after mating impairs olfaction and prevents odor interference with pregnancy. Nat Neurosci. 2008;11(8):949-56.

33. Shingo T, Gregg C, Enwere E, Fujikawa H, Hassam R, Geary C, Cross JC, Weiss S. Pregnancy-stimulated neurogenesis in the adult female forebrain mediated by prolactin. Science. 2003;299(5603):117-20.

34. Sultan S, Mandairon N, Kermen F, Garcia S, Sacquet J, Didier A. Learningdependent neurogenesis in the olfactory bulb determines long-term olfactory memory. FASEB J 2010;24(7):2355-63.

35. Valley MT, Mullen TR, Schultz LC, Sagdullaev BT, Firestein S. Ablation of mouse adult neurogenesis alters olfactory bulb structure and olfactory fear conditioning. Front Neurosci 2009;3:51.

36. Whitman MC, Greer CA. Adult neurogenesis and the olfactory system. Prog Neurobiol. 2009;89(2):162-75.

37. Yamaguchi M, Mori K. Critical period for sensory experience-dependent survival of newly generated granule cells in the adult mouse olfactory bulb. Proc Natl Acad Sci U S A. 2005;102(27):9697-702.

38. Zhao C, Deng W, Gage FH. Mechanisms and functional implications of adult neurogenesis. Cell. 2008;132(4):645-60. 


\section{Figure legends}

Figure 1. Adult neurogenesis and the olfactory system. Neurons born in the subventricular zone (SVZ) of the lateral ventricles (LV) migrate via the rostral migratory stream (RMS) into the olfactory bulb. The olfactory bulb consists of two structures, the main olfactory bulb (MOB) and the accessory olfactory bulb (AOB). The main and accessory olfactory bulbs receive signals from the main olfactory epithelium (MOE) and the vomeronasal organ (VNO), respectively.

Figure 2. Methods for inhibition of adult neurogenesis. (a) Inhibition of neurogenesis by $\gamma$-ray irradiation. A brain area encompassing the SVZ or SGZ is exposed to irradiation while the other brain region is protected with lead shields. (b) Inhibition of neurogenesis by administration of anti-mitotic drugs with an osmotic minipump. (c) Genetic ablation of newly born neurons. In Nestin-CreERT2;NSE-loxP-Stop-loxP-DTA mice, Cre is activated in neural stem/progenitor cells after tamoxifen administration, but DTA is not expressed in neural stem/progenitor cells because the NSE promoter is inactive in these cells. However, when these cells start neuronal differentiation, the NSE promoter becomes active and induces expression of DTA, which kills cells. Thus, in these mice, only newborn neurons are efficiently ablated after tamoxifen treatment. DTA, diphthelia toxin fragment A; NSE, neuron-specific enolase. 
Table 1. Olfaction-dependent behavior phenotypes of treated or mutant mice.

\begin{tabular}{|c|c|c|c|c|}
\hline Behavior tests & $\begin{array}{l}\text { Treatments/ } \\
\text { Genotypes }\end{array}$ & $\begin{array}{l}\text { Affected } \\
\text { regions }\end{array}$ & Phenotypes & References \\
\hline \multirow[t]{4}{*}{ Habituation-dishabituation } & $\gamma$-ray irradiation & SVZ & $\begin{array}{l}\text { Normal short-term } \\
\text { memory }\end{array}$ & 20 \\
\hline & AraC & SVZ & $\begin{array}{l}\text { Defective short- } \\
\text { term memory }\end{array}$ & 5,26 \\
\hline & $\mathrm{Bax} \mathrm{KO}$ & SVZ & $\begin{array}{l}\text { Normal short-term } \\
\text { memory }\end{array}$ & 18 \\
\hline & NCAM KO & SVZ & $\begin{array}{l}\text { Defective odor } \\
\text { discrimination }\end{array}$ & 13 \\
\hline \multirow[t]{4}{*}{ Odor-reward association } & $\gamma$-ray irradiation & SVZ & $\begin{array}{l}\text { Defective long-term } \\
\text { memory }\end{array}$ & 20 \\
\hline & AraC & SVZ & $\begin{array}{l}\text { Defective long-term } \\
\text { memory }\end{array}$ & 34 \\
\hline & $\begin{array}{l}\text { Nestin-CreER }{ }^{\mathrm{T} 2} \text {; } \\
\text { NSE-DTA }\end{array}$ & $\begin{array}{l}\text { SVZ } \\
\text { SGZ }\end{array}$ & $\begin{array}{l}\text { Normal short- and } \\
\text { long-term memory }\end{array}$ & 15 \\
\hline & NCAM KO & SVZ & $\begin{array}{l}\text { Normal short- and } \\
\text { long-term memory }\end{array}$ & 31 \\
\hline \multirow[t]{3}{*}{ Maternal behaviors } & $\gamma$-ray irradiation & SVZ & Normal & 12 \\
\hline & MAM & $\begin{array}{l}\text { SVZ } \\
\text { SGZ }\end{array}$ & Defective & 19 \\
\hline & $\begin{array}{l}\text { Nestin-CreER }{ }^{\mathrm{T} 2} \text {; } \\
\text { NSE-DTA }\end{array}$ & $\begin{array}{l}\text { SVZ } \\
\text { SGZ }\end{array}$ & Defective & 30 \\
\hline
\end{tabular}




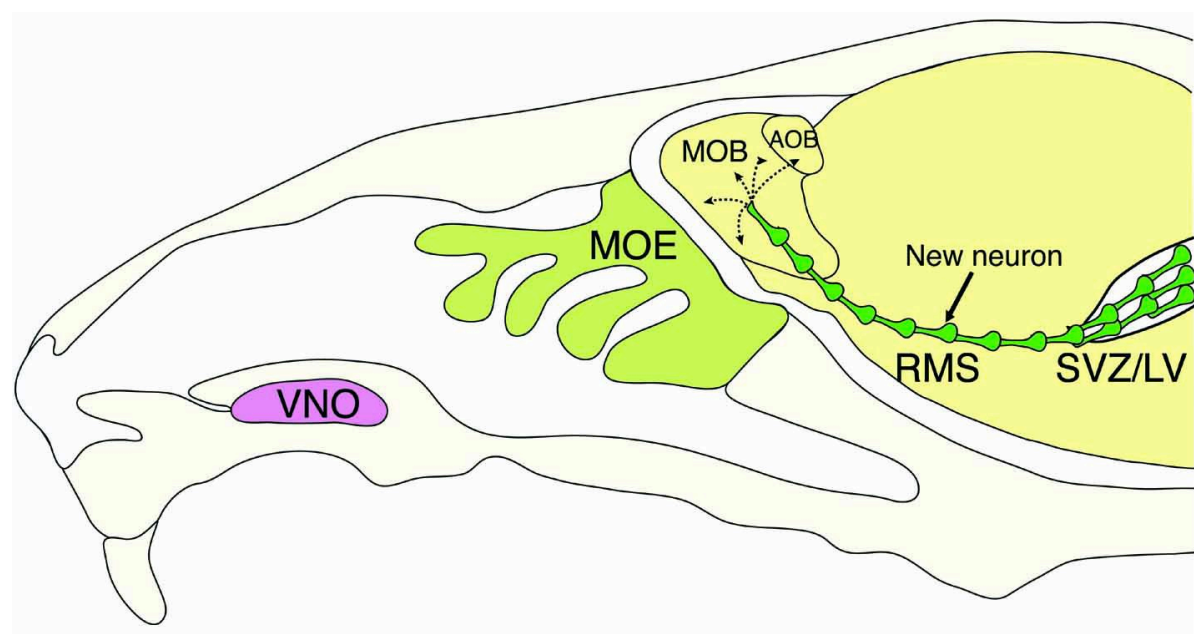

Figure 1 
a Irradiation

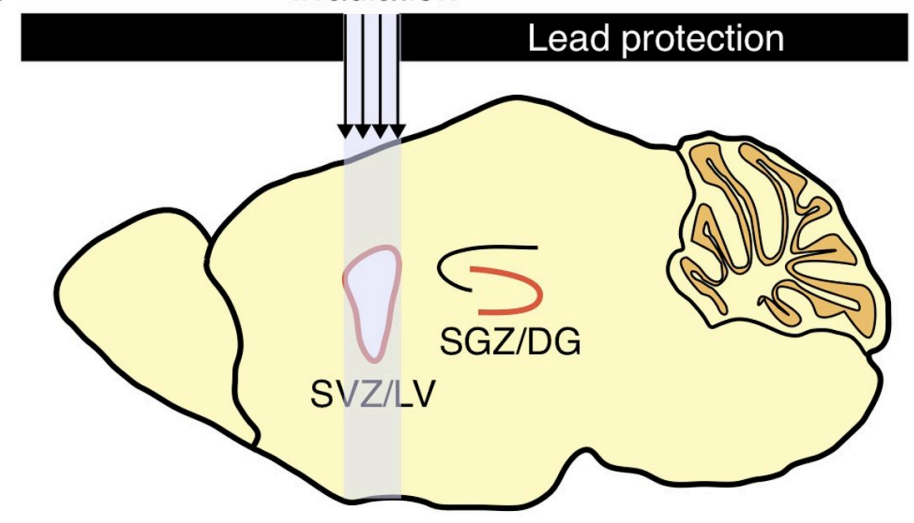

b

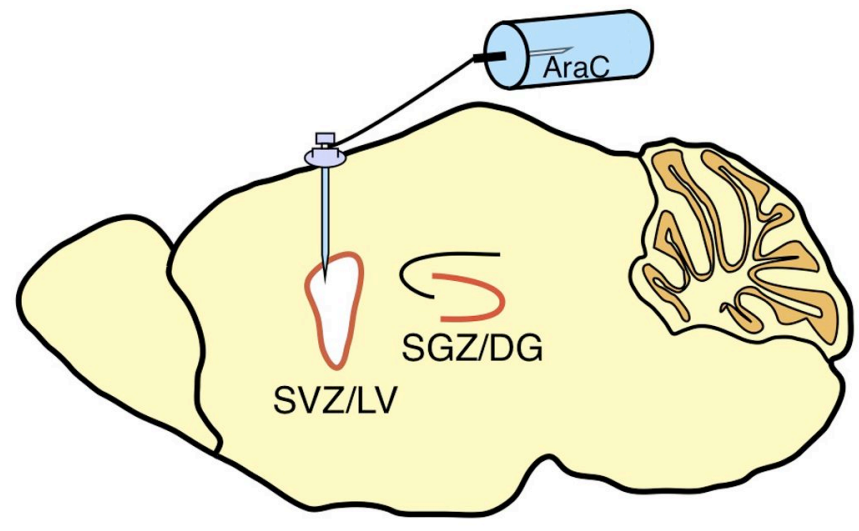

C

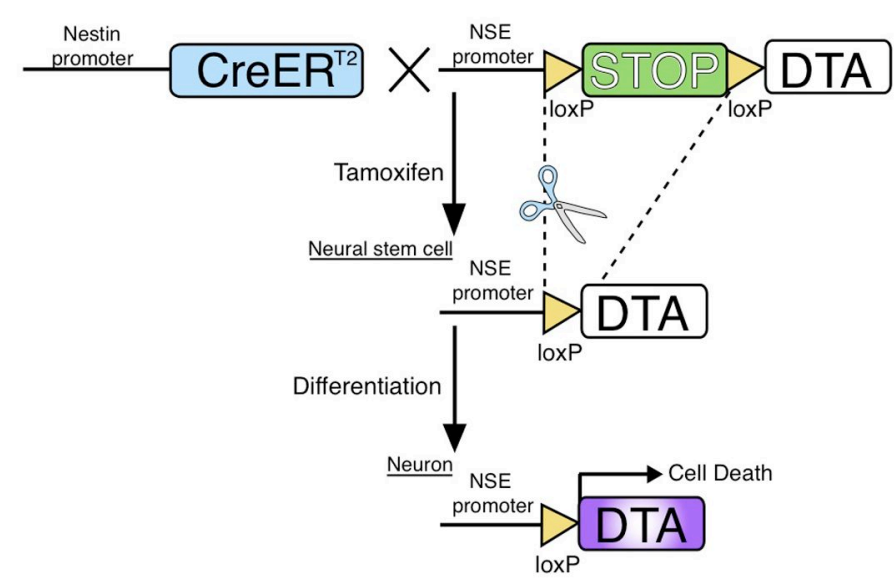

Figure 2 